\title{
A Message from an Old Master
}

\section{Phlogiston and the Hardening of Steel}

(C) Springer Science+Business Media New York and ASM International 2013

The following is an excerpt from a book by Albert Sauveur, published in 1935, entitled "Metallurgical Dialogue," dealing with (then) historical theories on the hardening of steel. Ideas discussed in this passage, presented as a dialog between a Master (M) and student (P for Pupil), describe how the "present" (early twentieth century) understanding of hardening of steel came about. It is a fascinating account, and reveals an amazing depth of understanding in regard to the role of carbon in steel even back to the eighteenth century. Reference is made to the importance of phlogiston, and the amazing properties of Toledo and Damascus blade steel. The core of this excerpt focuses on the work of Percy, an Englishman who published his ideas in a book entitled "Metallurgy" in the late 1800s, and discusses advances in understanding made since that time (Fig. 1).

- C.B.

\section{In Lieu of a Preface}

I find it difficult to follow the custom which demands that, in his preface, an author, with becoming modesty, should depreciate the value of what he has to offer, assuring the reader that he is well aware that it is unworthy of his (the reader's) intelligence and culture, and that he should then attempt to convince as large a portion of the public as possible, that its salvation depends upon the reading of his book.

My difficulty proceeds from my inability to think of a single good reason why any one should read this conversation with an imaginary student-That I have found pleasure and profit in conducting it does not signify that others should find in reading it either pleasure or instruction.
My only hope is that my failure to provide a preface may win the gratitude of my readers and their indulgence.

\author{
Albert Sauveur \\ Harvard University, \\ Cambridge, Massachusetts, \\ July, 1935
}

\section{Metallurgical Dialogue}

$P$. Is it possible that after having practiced the art of hardening steel by rapid cooling for hundreds if not for thousands of years, metallurgists are not yet able to offer a fully acceptable explanation of that phenomenon?

$M$. I shall leave that conclusion to you. Let us consider briefly the attempts that have been made and the various theories offered.

$P$. I have the impression that we are on the threshold of a lengthy discussion.

$M$. I share your impression, but I shall try to make it as short as is consistent with clarity. Let us proceed in a chronological order. Let us read from "Encyclopédie ou dictionnaire raisonné des sciences, des arts et des métiers, par une société de gens de lettres mis en ordre et publié par M. Diderot; et quant à la partie mathématique, par M. D'Alembert," published in 1778.

$P$. That is a formidable title. It also requires a reading knowledge of French to know what it is all about.

$M$. Let us proceed. It will be interesting to know what they considered at the time to be the nature of steel. It reads as follows, translating for your benefit: "Steel is nothing but very pure iron, in which by various means as much phlogiston as possible has been introduced-to convert 
iron into steel, therefore, it is only necessary to increase the phlogiston it already contains, in mixing with it, in closed vessels, substances which contain much fatty matter such as horn, hair and other animal or vegetable substances loaded with the combustible principle."

"M. Lauraeus says that one may successfully harden delicate tool steels in the juice of garlic: the operation consists in cutting some garlic in small pieces and in covering them with 'eau-de-vie.' They are kept for twentyfour hours in a warm place. The liquid is then passed through a linen cloth and is kept in a well stoppered bottle to be used as required." This gives us an insight into the views held by early metallurgists concerning the nature of steel and the quenching or hardening operation. It can be summarized in a few words: to make steel, put as much phlogiston in iron as you can; to harden steel cooled rapidly from a high temperature in order to retain the phlogiston you have put in.

$P$. Is it not surprising that with such crude notions they were able to produce such unsurpassed steel articles as Toledo and Damascus blades?

$M$. It shows what extraordinary skill can be acquired by artisans, even when it results solely from the accumulated empirical knowledge transmitted from generation to generation and often from father to son.

Let us now take a broad jump, from 1778 to 1864, when the great English metallurgist Percy published his "Metallurgy," and note what advance had been made in that period of nearly one hundred years concerning possible explanations of the hardening of steel by quenching. Let us read from Percy:

When steel is heated to redness, and then plunged while red hot into cold water, or is otherwise suddenly cooled, it acquires great hardness and brittleness.... It has long been known that by hardening, steel expands sensibly, and consequently decreases in specific gravity. Réaumur seems first to have recorded the results of accurate experiments on the subject; 'M. Perrault,' he writes 'has already observed before us that a steel wire after hardening could not pass through the same hole as before hardening; I have repeated this experiment in many different ways, and I have always found an increase of volume in hardened steel; but I wished further to ascertain the extent of this increase, and whether it was sufficient to admit of being determined by measurement. I had made callipers of iron, in which a piece of steel, 6 inches long, just fitted; my pieces of steel were usually 2 inches wide by 6 lines thick. After they had, in the processes of hardening, acquired a whitish red color, I always found them at the least one line longer than in the original, soft state: there was increase in

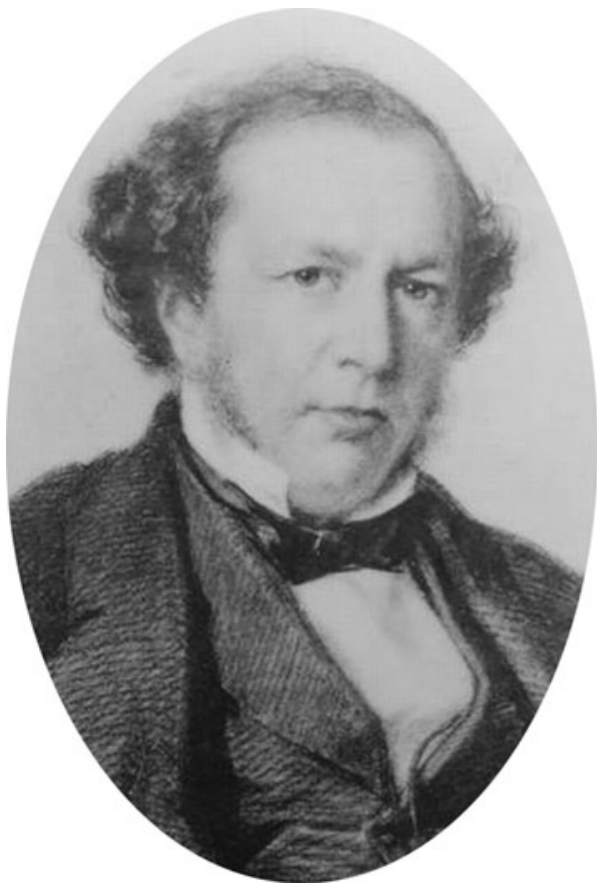

Fig. 1 Dr. John Percy (1817-1889) was born in England in March 1817. He started his career as a medical doctor but developed a passion for metallurgy in 1846 when he became interested in the metals industry. During his time as a metallurgist, Percy wrote several key books and numerous papers on metallurgical processes. One of these papers included the process of extracting silver from its ores. He passed away in June 1889 just after receiving the prestigious Albert Medal of the Royal Society of Arts for his contribution to the progress of the science of metallurgy

other directions, as well as lengths, but this it was not so easy to measure as elongation; that is no reason for doubting that it was proportionate to the increase in length... Réaumur computed that in the process of hardening steel increased $1 / 48$ in volume.

$P$. One would expect that when red-hot steel is plunged into cold water it would contract more than when permitted to cool slowly and that hardened steel, therefore, would have a higher specific gravity. How is this increase of volume explained?

$M$. The recent information obtained from X-ray diffraction analysis may supply an explanation. Both in the slowly cooled and in the hardened steel, the iron is present in the alpha condition which you may remember has a body-centered cubic space lattice. In the slowly cooled steel, however, the carbide of iron (cementite) has completely left the space lattice of the ferrite, being present as cementite plates in the pearlite and, in hypereutectoid steel, also as excess or free cementite. The space lattice of the alpha ferrite is of normal dimensions and undeformed. In the quenched steel, on the contrary, numerous extremely minute particles of cementite are believed to be present 
resulting in a distorted, somewhat expanded space lattice, thus accounting for the larger volume or smaller specific gravity of quenched steel.

It should be added that the existence of a tetragonal space lattice in quenched steel has been observed by many; that is, of a lattice which may be considered as a transition form between the face-centered lattice of gamma iron and the body-centered lattice of alpha iron. I shall have occasion in the course of our discussion to refer to this interesting phenomenon.

The presence of gamma lines is also frequently observed in the spectrum of hardened steel indicating the retention of some undecomposed (retained) Austenite.

$P$. The occurrence of these minute particles of cementite in hardened steel recalls the aging of metals and alloys.

$M$. It does and we shall soon see that the hardening of steel might be explained in the light of the precipitation theory.

$P$. Percy refers to steel increasing in length by one line. What is a line?

$M$. It is a measure of length sometimes given as onetwelfth of an inch, sometimes as one-tenth of an inch.

Let us read further from Percy:

Now, it appears to be established, that a piece of steel, which when hardened dissolves completely in hydrochloric acid, always yields a sensible amount of carbonaceous residue when subjected in the soft state to the action of the same solvent.... In molten, or even in strongly heated solid steel, the carbon is wholly combined, or, possibly, simply dissolved: and by sudden solidification of the metal in the one case, or sudden cooling of it in the other, the whole of the carbon remains diffused through the mass. However, the carbon may have separated notwithstanding, and exist in a state of infinitesimally fine divisions; and it is conceivable that it may be in the allotropic condition of graphite, and, may yet, owing to what I will venture to designate an atomic state of disaggregation, be capable of entering into combination with nascent hydrogen, and produce the residue supposed to be indicative of the presence of what is termed 'combined' carbon. Whether this view be correct or not, it is certain that hard and soft steel differ essentially with no regard to the mode of existence of the carbon in the mass... The particles of hardened steel are obviously in a state of tension, which may, probably, be analogous to the particles of glass in the annealed state; and, if the former were transparent, the polariscope would, it is reasonable to suppose, reveal a structure similar to that which it renders manifest in the latter.
$P$. Could you make a little clearer this possible existence of carbon under different forms in slowly cooled and in hardened steel?

$M$. Percy's views as to the different forms under which carbon may exist in steel are extremely interesting and testify to his clear vision. They have been verified by later investigations and they contain the germs of several theories on the hardening of steel that have been propounded since. It will be profitable to consider under what form carbon may exist in the light of modern research. It is well known that this element may occur as amorphous or graphitic carbon and also as crystalline carbon in the form of diamonds. It is also known that it may be combined with iron to form molecules of the carbide $\mathrm{Fe}_{3} \mathrm{C}$.

Sir Frederick Abel, in his final report to the Institution of Mechanical Engineers on "Hardening, Tempering and Annealing of Steel" in 1885 writes that "in annealed steel the carbon exists entirely, or nearly so, in the form of a carbide of iron, of uniform composition $\left(\mathrm{Fe}_{3} \mathrm{C}\right.$ or a multiple thereof) uniformly diffused through the mass of metallic iron".... that "in hardened steel the sudden lowering of the temperature from a red heat appears to have the effect of preventing or arresting the separation of the carbon, as a definite carbide, from the mass of iron in which it exists in combination."...that "in tempered steel the condition of the carbon is intermediate between that of hardened and annealed steel..."

In regard to the kind of association which may exist between carbon in its various forms and the iron with which it is alloyed we have to consider (1) the existence of carbon atoms within the space lattices of gamma and alpha iron forming with them solid solutions, (2) the possible existence of graphite particles in submicroscopic size and its known existence in microscopic or macroscopic dimensions, (3) the possible existence of diamond particles in submicroscopic or microscopic dimensions, and (4) the possible existence of particles of $\mathrm{Fe}_{3} \mathrm{C}$ in submicroscopic dimensions and its known existence in microscopic and macroscopic dimension.

$P$. I never thought that this simple element could be present in so many different particles sizes. Could you give some values of actual dimensions when you refer to submicroscopic, microscopic and macroscopic sizes?

$M$. The unaided eye cannot generally detect objects smaller than 0.01 inch, while the limit of the microscope is about 0.000001 inch under the highest magnification obtainable.

$M$. Submicroscopic dimensions, therefore, may be considered as including any size smaller than $0.000001 \mathrm{inch}$, microscopic dimensions any size between 0.000001 and 0.01 inch and macroscopic dimension any size equal to or greater than 0.01 inch. 
Percy calls attention to the difference in the behavior of carbon as present in hardened steel and in slowly cooled when subjected to the action of some acids. Those results have been fully confirmed. The question, however, as to whether this difference of behavior is caused by an actual difference in the chemical form in which the carbon occurs or to a different mode of association with the iron, or again to particle size is still debated. Let us consider briefly these possibilities. When hardened steel is treated with hydrochloric acid, it is completely dissolved, whereas when slowly cooled steel is so treated a carbonaceous residue remains. It is now known that upon analysis this residue is found to correspond closely to the formula $\mathrm{Fe}_{3} \mathrm{C}$ which calls for $6.67 \%$ carbon, hence the logical conclusion that in slowly cooled steel the carbon exists as the carbide $\mathrm{Fe}_{3} \mathrm{C}$. This has been called also cement carbon and later by Howe cementite. It would seem justified to infer that in hardened steel carbon must exist under another form, since little, if any, residue remains after solution in hydrochloric acid. That was the conclusion reached and this form of carbon came to be known as hardening carbon.

Before dismissing the possibility of carbon existing in hardened steel in the form of $\mathrm{Fe}_{3} \mathrm{C}$, it is well to consider that it might exist in that form but in submicroscopic dimensions which would account for its being acted upon more readily by the acid. Indeed one of the most attractive theories of this hardening of steel, the precipitation theory, demands, as we shall see, this precipitation of the carbide in submicroscopic size. Is it not conceivable that particles measuring possibly 0.00001 inches in diameter would go into solution quite readily, whereas particles measuring some 0.001 ; that is, one hundred times larger, would fail to do so or at least would dissolve very slowly?

Taking up the argument that carbon cannot be present as $\mathrm{Fe}_{3} \mathrm{C}$ in hardened steel, it naturally follows that it must be present in atomic dispersion as the possible existence of graphite particles can hardly be entertained. This implies that it is retained in solid solution in alpha iron, a view held by some which we shall discuss a little later. I shall also postpone any further reference to the possible existence of diamond particles.

While we are discussing the occurrence of carbon in steel, we should consider the behavior of steel when dissolved in dilute nitric acid for the purpose of estimating the carbon content by the so-called color method. Slowly cooled steel imparts to the solution a deep coloration, whereas hardened steel colors it very much less. Indeed, using annealed steel as a standard, it is found that hardened steel appears to contain but about one-half as much carbon. The other half is known as "missing" carbon. One naturally is led to ask whether this "missing" carbon is not identical to the "hardening" carbon and also to submicroscopic $\mathrm{Fe}_{3} \mathrm{C}$-which brings us back to our query; is carbon in hardened steel present in solid solution, or is it present as $\mathrm{Fe}_{3} \mathrm{C}$ in submicroscopic size or possibly in both forms? This will soon lead us to a consideration of the modern theories.

(To be continued.... Look for further excerpts from Metallurgical Dialogue in future issues of Metallography, Microstructure, and Analysis.) 